\title{
Distribution of Facial Motoneurons Innervating the Common Facial Muscles of the Rabbit and Rat
}

\author{
By \\ Rui FURUTANI ${ }^{1}$, Tetsuya IZAWA ${ }^{2}$ and Shoei SUGITA ${ }^{3}$ \\ ${ }^{1,2}$ Graduate School of Science, Tokyo Metropolitan University \\ ${ }^{3}$ Department of Animal Science, Utsunomiya University
}

- Received for Publication, November 15, $2004-$

\begin{abstract}
Key Words: facial muscle, facial nucleus, horseradish peroxidase, rabbit, rat
Summary: The distribution of the facial neurons that innervate several facial muscles was determined in the rabbit and the rat by examining the retrograde transport of horseradish peroxidase (HRP). The target muscles were musculus levator nasolabialis, $\mathrm{m}$. levator labii superioris, $\mathrm{m}$. zygomaticus, and $\mathrm{m}$. buccinator pars buccalis, as well as $\mathrm{m}$. parietoauricularis and $\mathbf{m}$. depressor anguli oris in the rabbit and $\mathbf{m}$. levator auricularis posterioris in the rat. Localization of the retrogradely labeled neurons within the ipsilateral facial nucleus was confirmed for all facial muscles examined. Our results showed that $\mathrm{m}$. levator nasolabialis was innervated by neurons located in the dorsal subnucleus, while the motoneurons innervating $\mathrm{m}$. buccinator pars buccalis were distributed within the dorsal part of the intermediate subnucleus of the facial nucleus in the both species. Localization of the labeled motoneurons innervating m. zygomaticus and $\mathrm{m}$. levator labii superioris showed the difference in the distribution within the facial nucleus among the species. Neurons innervating $\mathbf{m}$. parietoauricularis and $\mathbf{m}$. levator auricularis posterioris were localized in somewhat different subregions of the medial subnucleus in these species. M. depressor anguli oris was innervated by the neurons distributed within the intermediate subnucleus of the facial nucleus in the rabbit. Thus, our findings revealed that there is speciesspecific motor innervation pattern in rabbits and rats, despite several movement of the face is supplied by the homologous facial muscles.
\end{abstract}

The distribution of the neurons corresponding the facial muscle within the facial nucleus was described for several species including the mouse, rat, guinea pig, cat, blush-tailed opossum, rhesus monkey and japanese monkey (Provis et al., 1977; Kume et al., 1978; Shohara et al., 1983; Watson et al., 1984; Komiyama et al., 1984; Uemura-Sumi et al., 1986; Morecraft et al., 2001). Especially, many investigaters have showed the suggestions about the projection system in the rodents (Martin et al., 1977). These studies indicate the clear-cut somatotopic representation of the facial musculature and the muscle branches of the facial nerve within the facial nucleus of the rat and the mouse (Watson et al., 1982; Komiyama et al., 1984). While the superficial group of facial muscles was shown to be innervated by the neurons within the main facial nucleus (Shohara et al., 1983), the deep facial muscles such as the stylohyoid muscle and the posterior belly of the digastric muscle were shown to be innervated by the neurons located in the intermediate subnucleus and suprafacial nucleus in the mouse (Watson et al., 1982). Mapping the innervation of the facial muscles within the facial nucleus have been demonstrated by various methods such as the retrograde cell degeneration technique, the antidromic field-potential and the retrograde horseradish peroxidase labeling (Provis et al., 1977; Kume et al., 1978; Watson et al., 1982; Shohara et al., 1983; Komiyama et al., 1984; Morecraft et al., 2001). However, the localization of facial neurons innervating the facial musculature has not been identified clearly in the rabbits despite the somatotopic representation of the muscle branches of the facial, hypoglossal and trigeminal nerve are identified within the particular nuclei of the rabbits (UemuraSumi et al., 1988; Satoda et al., 1988). Individual muscle branch of the facial nerve provides the movement of several facial muscles in rodents (Watson et al., 1982; Komiyama et al., 1984). Mapping the functional subdivisions of the facial nucleus requires the identification of group of neurons that innervate individual facial muscles. The goal of the present study was to identify the somatotopic representation of the facial muscles within the facial nucleus of the rabbits using the HRP technique. 
Furthermore, the relationship between the motor innervation of the facial muscles across the species were investigated in rabbits and rats by the application of the HRP to common and convergent facial muscles in these animals.

\section{Materials and Methods}

\section{Animals}

Fifteen female Wistar rats weighting approximately 200-250 g and eighteen female breed of Japanese white rabbits weighting approximately $1 \mathrm{~kg}$ were used in this study for the retrograde transport of horseradish peroxidase (HRP) study. Three animals were used to investigate the innervation of each muscles in these animals. All animal experimentation was carried out under the anesthesia in accordance with the guidelines of the Animal Care and Use Committee of Utsunomiya University. All efforts were made to minimize animal suffering and to reduce the number of animals used.

\section{Retrograde tracer technique}

Animals were anesthetized with sodium pentobarbital $(45 \mathrm{mg} / \mathrm{kg}$ for the rat, $40 \mathrm{mg} / \mathrm{kg}$ for the rabbit). The skin around the right auricle, and nasolabial and cervical region was incised to exposure the target facial muscles. A $30 \%$ solution of HRP dissolved in distilled water, was injected into four right facial muscles i.e., m. levator nasolabialis, $\mathrm{m}$. levator labii superioris, m. zygomaticus, and $\mathrm{m}$. buccinator pars buccalis, as well as m. parietoauricularis and $\mathrm{m}$. depressor anguli oris in the rabbits and $\mathrm{m}$. levator auricularis posterioris in the rats. Following a survival period of $48 \mathrm{~h}$, the animals were overdosed on sodium pentobarbital $(75 \mathrm{mg} / \mathrm{kg}$ for the rats; $50 \mathrm{mg} / \mathrm{kg}$ for the rabbits) and were perfused transcardially with a buffered aldehyde mixuture consisting of $1.25 \%$ glutaraldehyde and $1 \%$ paraformaldehyde in $0.1 \mathrm{M}$ phosphate buffer ( $\mathrm{pH}$ 7.4), followed by a sucrose buffer wash. The brains were immediately removed and immersed in a $20 \%$ sucrose-containing, phosphate-buffered solution until they sank, and cut transversely at 70 micrometer on the freezing microtome. For the histochemical demonstration of HRP, the sections were treated with tetramethylbenzidine (Mesulam et al., 1976, 1979), then mounted on gelatinized slides, and counterstained with $1 \%$ neutral red.

\section{Results}

Following HRP injection, retrogradely labeled neurons that innervated particular facial muscles were identified within the ipsilateral facial nucleus. Labeled neurons corresponding to individual facial muscles showed the difference in the distribution within the subnuclei of the facial nucleus. Moreover, the retrogradely labeled motoneurons showed the distinct number and length within the facial nucleus that those occurred.

M. levator nasolabialis in the rabbits and the rats are innervated by the buccolabial branch of the facial nerve. Retrogradely HRP-labeled neurons were distributed within the dorsal part of the dorsal subnucleus by the injection into $\mathrm{m}$. levator nasolabialis in the rats (Figs. 2A, 4D, and 4F) and the rabbits (Figs. 2B and 4C). However, differences were observed in the distribution of the labeled neurons within the dorsal facial subnucleus (Figs. 2A, B and 4C, D, F). Labeled neurons innervating $\mathrm{m}$. levator nasolabialis in the rabbit scattered around the dorsal area of the dorsal subnucleus, whereas those of the rat were situated only within the dorsal part of the dorsal subnucleus (Figs. 2A, $\mathrm{B}$ and $4 \mathrm{C}, \mathrm{D}, \mathrm{F})$. The number of the labeled neurons was $151 \pm 13$ by the injection into $\mathrm{m}$. levator nasolabialis of the rabbits (mean $\pm \mathrm{SD} ; \mathrm{n}=3$ in all cases), whereas those of the rats totaled $56 \pm 6$ $(n=3)$.

Labeled neurons innervating $\mathrm{m}$. buccinater pars buccalis were localized to the dorsal part of the intermediate subnucleus of the facial nucleus in both rats and rabbits (Fig. 2A and B). The total number of the retrogradely labeled neurons of the rabbits was greater than those of the rats $(234 \pm 110$ in the rabbit, $37 \pm 12$ in the rat).

Localization of the labeled neurons within the facial nucleus showed the difference in the distribution among the species by the injection into $\mathrm{m}$. levator labii superioris and $\mathrm{m}$. zygomaticus. Neurons innervating $\mathrm{m}$. zygomaticus in the rats localized to the ventrolateral part of the medial subnucleus and dorsomedial part of the intermediate subnucleus (Fig. 3A), while those in the rabbits distributed through dorsolateral to ventrolateral area within the medial subnucleus (Fig. 3B). Labeled neurons numbered $31 \pm 12$ by the injection into $\mathrm{m}$. zygomaticus of the rabbits, whereas the number of labeled neurons was $18 \pm 4$ by the injection into $\mathrm{m}$. zygomaticus of the rats.

Labeled neurons were identified within the dorsolateral part of lateral subnucleus by the injection of HRP into $\mathrm{m}$. levator labii superioris of the rabbits (Figs. 2B, 4A), whereas those of the rats were distributed within the ventromedial part of the dorsal subnucleus, and ventrolateral part of the intermediate subnucleus and the lateral subnucleus (Figs. 2A, 4B). Total number of the labeled neurons was $813 \pm 76$ by the injection into $\mathrm{m}$. levator 

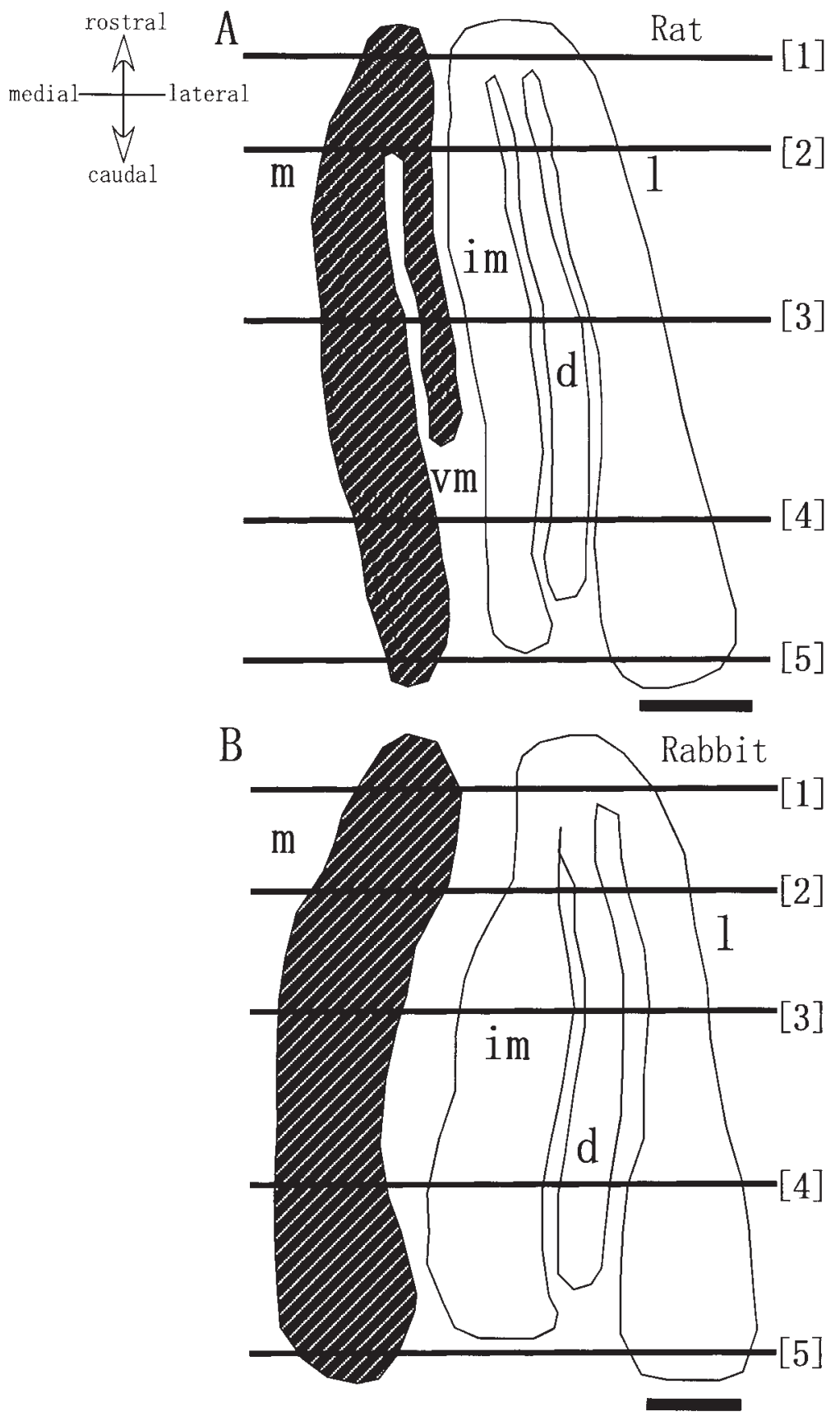

Fig. 1. Schematic drawings represent the right facial nucleus in the rat (A) and rabbit (B) which viwed dorsally. The rostrocaudal level of facial nucleus were divided into five level, [1]-[5] parallels to that showed in Fig. 2 and 3. All scale bars indicate 300 micrometer. m: medial subnucleus, vm: ventromedial subnucleus, im: intermediate subnucleus, l: lateral subnucleus, d: dorsal subnucleus of the facial nucleus.

labii sperioris of the rabbits $(\mathrm{n}=3)$, whereas those of the rats numbered $390 \pm 23$ by the injection into $\mathrm{m}$. levator labii sperioris of the rats $(\mathrm{n}=3)$.

Retrogradely labeled neurons were identified within the ventromedial part of the medial subnucleus following the injection of HRP into m. parietoauricularis of the rabbits (Fig. 3B), and labeled neurons innervating $\mathrm{m}$. levator auricularis posterioris of the rat were distributed through medial to ventromedial region within the medial subnucleus (Fig. 3A). Localization of the retrogradely labeled neurons showed the similar somatotopic representation within the facial nucleus despite these muscles were distinct auricular muscle across the 


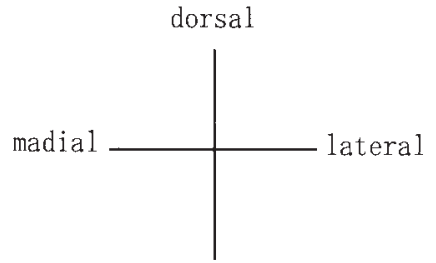

vantral
[1]<smiles>[AlH2]</smiles>

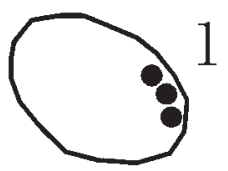

d
[2]

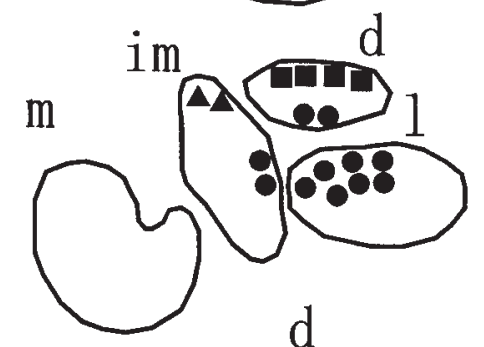

$[3]$

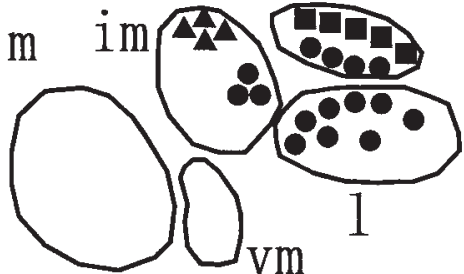

[4]

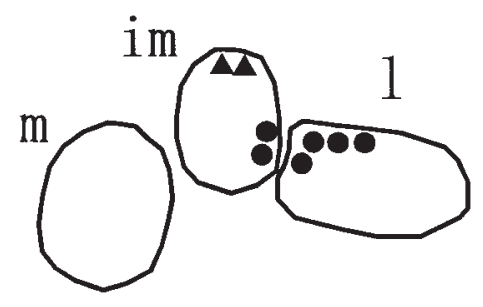

[5]

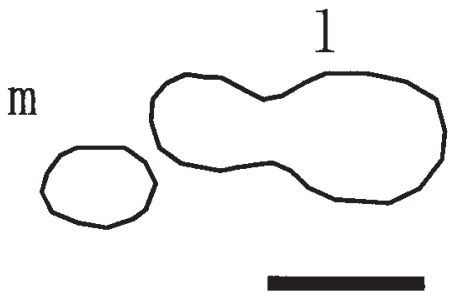

[1]<smiles>[R]C1CCCCCC1</smiles><smiles>Cl[C@H]1CC[C@H]2CC[C@H]1C2</smiles>

[2]

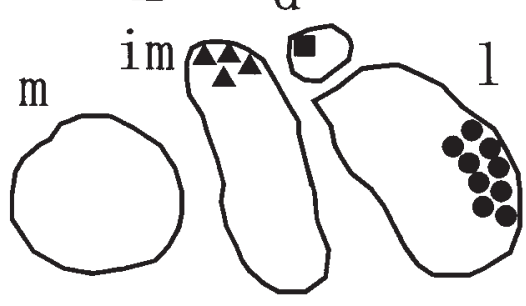

[3]

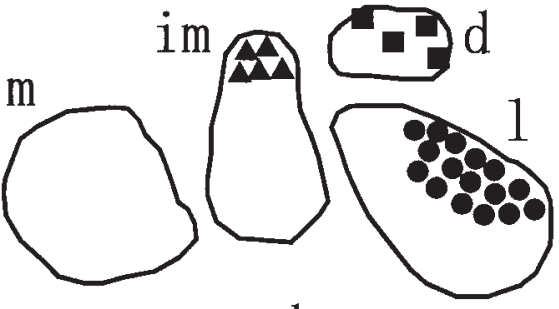

d

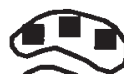

AM. buccinator pars buccalis

M. levator labii superioris 


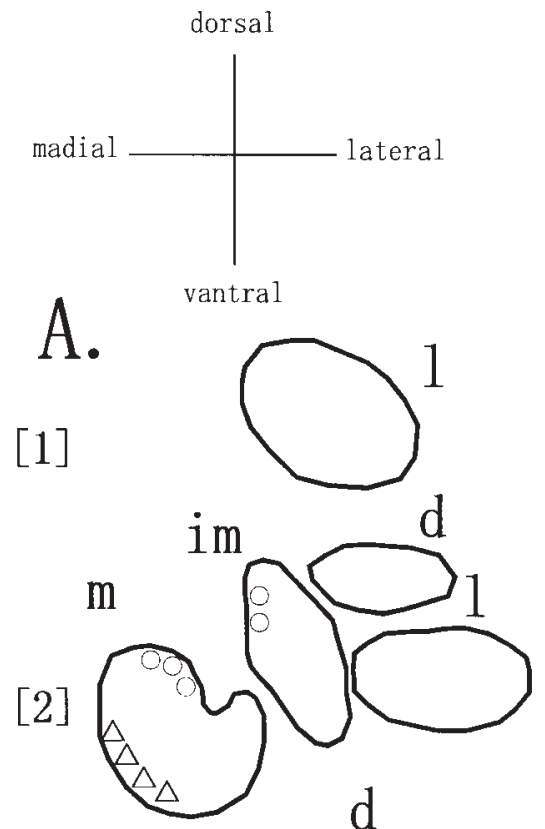

$\square$ M. parietoauricularis

$\triangle M$. levator auricularis posterioris

OM. zygomaticus

H. depressor anguli oris

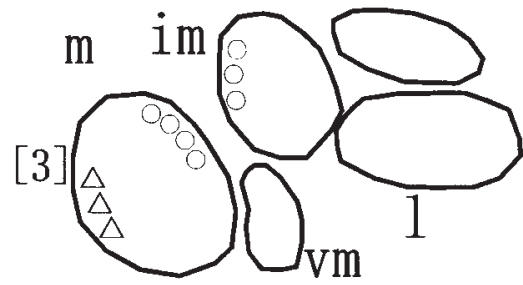

B.

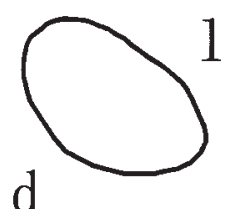

im

$[2]$
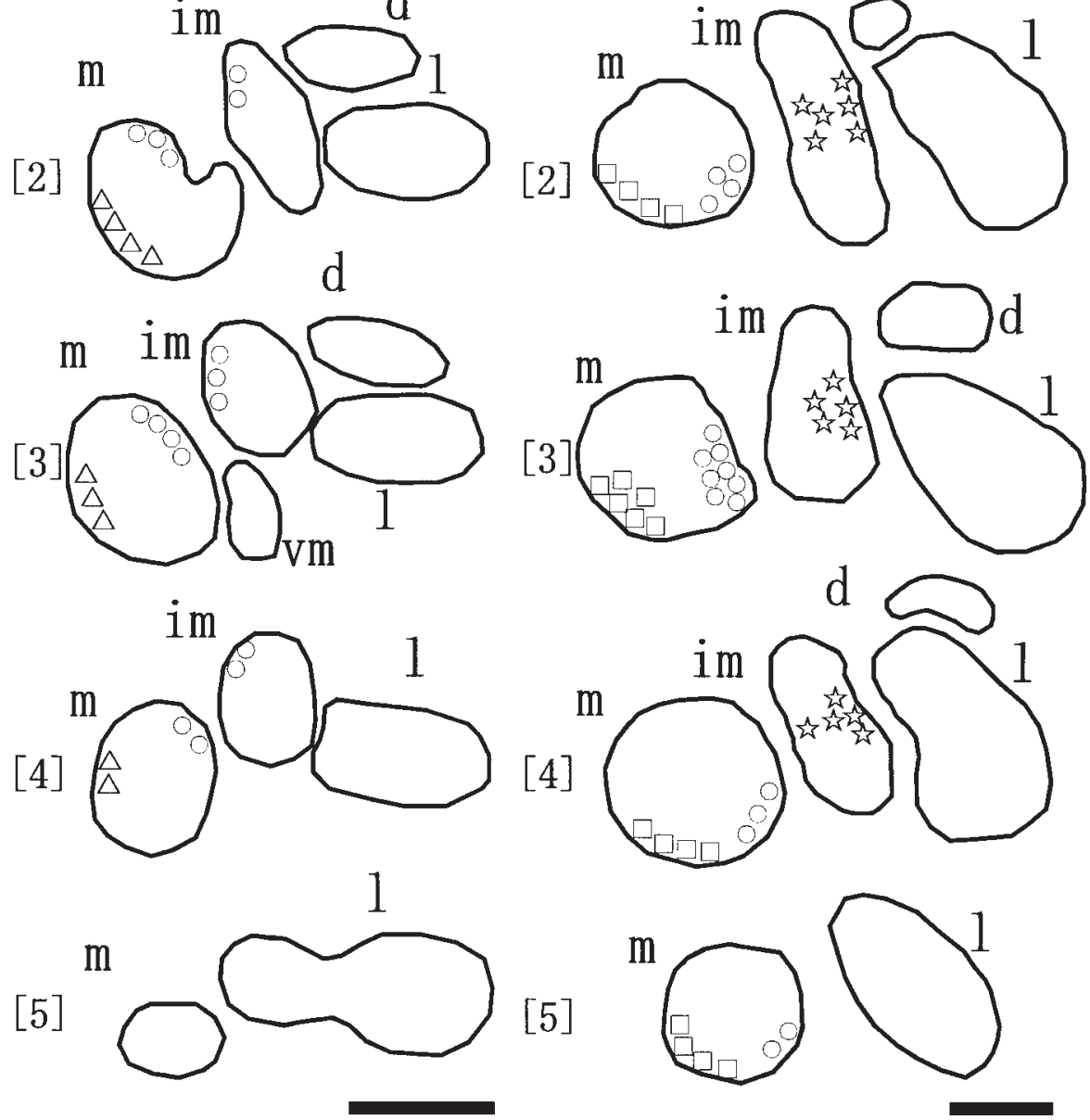

Fig. 3. Diagrams represent the distribution of labeled motoneurons within the right facial nucleus of the rats (A) and rabbits (B) in the transverse section, following the HRP injection into the distinct facial muscles. The four symbols correspond to the retrogradely labeled facial neurons by the HRP injections into the individual facial muscles which designated in the upper right. And [1]-[5] correspond to coronal sections observed in the rostrocaudal level of facial nucleus showed in Fig. 1 and 2. All scale bars indicate 300 micrometer. m: medial, vm: ventromedial, im: intermediate, l: lateral and d: dorsal subnucleus of the facial nucleus.

species. The total number of the labeled neurons was $135 \pm 79$ by the injection into $\mathrm{m}$. parietoauricularis of the rabbits $(\mathrm{n}=3)$, whereas those of the rat numbered $32 \pm 4$ by the injection into $\mathrm{m}$. levator auricularis posterioris of the rats $(\mathrm{n}=3)$.

Retrogradely labeled neurons innervating $\mathrm{m}$ depressor anguli oris in the rabbits were localized to the central and lateral part of the intermediate subnucleus of the facial nucleus (Figs. 3B, 4E). The total number of the labeled neurons was $212 \pm$ 66 by the injection into $\mathrm{m}$. depressor anguli oris $(\mathrm{n}=3)$. 

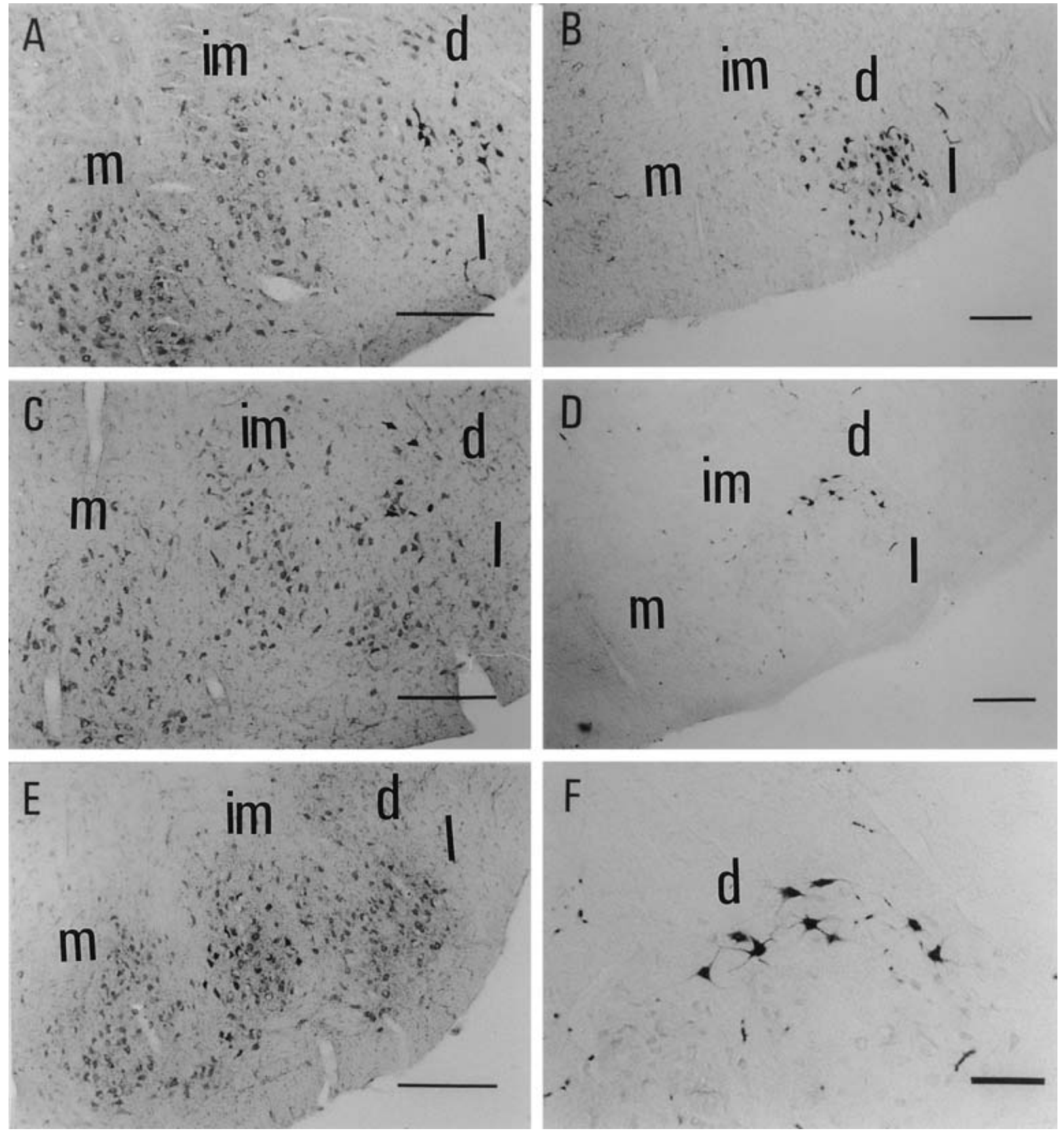

Fig. 4. Photomicrographs of the labeled neurons within the right facial nucleus in the transverse planes, following an injection into $\mathrm{m}$. levator labii superioris in the rabbit (A), $\mathrm{m}$. levator labii superioris in the rat (B), m. levator nasolabialis in the rabbit (C), $\mathrm{m}$. levator nasolabialis in the rat $(\mathrm{D}, \mathrm{F})$, and $\mathrm{m}$. depressor aunguli oris in the rabbit $(\mathrm{E})$. Scale bars indicate 300 micrometer (A-E), 100 micrometer (F). m: medial, vm: ventromedial, im: intermediate, l: lateral and d: dorsal subnucleus of the facial nucleus.

\section{Discussion}

The present study performed the somatotopic representation of the facial muscles in the facial nucleus of the rabbit and rat. The somatotopic representation of the facial muscles and the muscle branches of the facial nerve in the rodents have been previously reported (Watson et al., 1982; Shohara et al., 1983; Komiyama et al., 1984; Tsai et al., 1993). Our findings in the rat are in agreement with these prior results. Moreover, also in the several species such as the cat, blush-tailed opossum, 
rabbit, guinea pig, rhesus monkey and japanese monkey, the topographycal representation of the muscle branches of the facial nerve are identified within the facial nucleus (Provis et al., 1977; Kume et al., 1978; Shohara et al., 1983; Watson et al., 1984; Komiyama et al., 1984; Satoda et al., 1986; UemuraSumi et al., 1986; Welt et al., 1990; Morecraft et al., 2001). However, the topographic relationship of the facial motoneurons within the facial nucleus to individual facial muscles has, to date, not been reported in the rabbit. Our finding revealed the presence that individual facial muscles that located around the nasolabial area and auricle are innervated by the specific group of neurons which distributed in the particular area of distinct subnuclei of the facial nucleus in the rabbits. The results of the retrograde HRP mothods in the present study showed the suggestion that also in the rabbit, the anteroposterior axis in the face was projected lateromedially on the facial nucleus in the same manner which suggested in the previous study (Watson et al., 1982). However, this findings should be confirmed in all of facial muscles in the rabbits.

Motoneurons innervating $\mathrm{m}$. buccinator pars buccalis and $\mathrm{m}$. depressor anguli oris, which are innervated by the buccolabial branch of the facial nerve of rabbits, were localized in the intermediate subnucleus. This finding is consistent with the result of Satoda's study which suggested that the intermediate subnucleus in rabbits innervated the oral angular, inferior labial, and submandibular regions through the buccolabial branch which communicates with the superior and inferior labial branches of the facial nerve. Moreover, the neurons that innervated $\mathrm{m}$. buccinator pars buccalis in both the rat and rabbit were similarly ditributed in the dorsal part of the intermediate subnucleus. These findings suggest a common source for the control of contraction of $\mathrm{m}$. buccinator pars buccalis among the species.

The distribution of neurons within the dorsal facial subnucleus that innervated $\mathrm{m}$. levator nasolabialis of rats in the present study was similar to that reported by Watson et al. (1982). Localization of neurons corresponding $\mathrm{m}$. levator nasolabialis of the rabbit was similar to the result of those of the rat. A similar innervation pattern was reported in the mouse (Komiyama et al., 1984). However, differences were observed in the distribution within the dorsal subnucleus in the rat and the rabbit. These disparities may be due to differences in the cytoarchitectural organization of the dorsal subnucleus. The distribution of the labeled motoneurons that innervated $\mathrm{m}$. levator nasolabialis in the rabbits also appeared to reflect these cytoarchitectonic subdivisions as well. Although these sub- divisions of the facial nucleus are slightly different from the species to species, our findings suggest that the representation of the facial muscle innervation within the facial nucleus is similar in both rats and rabbits. Especially, the nasolabial movements that rodents such as rats and mice engage in may base their similarity on their homologous pattern of motor innervation by the dorsal subdivision of the facial nucleus.

The localization of the retrogradely HRPlabeled neurons corresponding $\mathrm{m}$. zygomaticus in rabbits was observed through dorsolateral to ventrolateral area of the medial subnucleus, despite $\mathrm{m}$. zygomaticus in rats was innervated by neurons distributed within the intermediate subnucleus, in addition, within the medial subnucleus. These results support the suggestion of others that movement of the auricle was due to the activity of neurons located in the medial subnucleus (Kume et al., 1978; Eckhard et al., 1985; Satoda et al., 1986). Our finding suggest that the movement of the auricle in rats was due to the activity of neurons located within the intermediate and medial subnuclei. Difference in the location of these neurons in rats and rabbits may have been developmentally influenced by whether or not m. zygomaticoauricularis, which runs in the same plane as m. zygomaticus in the rabbit, was present. Thus, $\mathrm{m}$. zygomaticus of the rat may be more abundantly innervated than that of the rabbit in order to allow for the adequate control of auricular movement by m. zygomaticus.

Neurons innervating $\mathrm{m}$. levator labii superioris were localized to the dorsal part of the lateral subnucleus in the rabbit. Interestingly, this findings of the rabbit differed from what we observed in the rat, where this muscle was found to be innervated by the lateral, intermediate, and dorsal subnuclei. A possible explanation for this apparent difference may be due to the fact that the lip was segmented by the philtrum between the orders of rodentia and lagomorpha. As a result, m. levator labii superioris in the rat may receive more abundant facial nerve innervation than those in the rabbit. These differences in the motor innervation of $\mathrm{m}$. levator labii superioris may reflect the important biological need to exquisitely control the nasolabial area. Sniffing, which is one of the most familiar behaviors which are observed in rodents, allows these animals to sample the physical and chemical environment. Sniffing requires the activation of several facial muscles that are located around the nasolabial area such as $\mathrm{m}$. levator nasolabialis and $\mathrm{m}$. levator labii superioris. This behavioral trait may have influenced the evolution of species-specific motor innervation.

The distribution pattern described for moto- 
neurons that supply the movement of $\mathrm{m}$. parietoauricularis, which is innervated by the posterior auricular branch of the facial nerve, was similar to that reported previously (Kume et al., 1978; Eckhard et al., 1985; Satoda et al., 1986). Our results specifically suggest that the anterior and posterior auricular branches of the facial nerve contain fibers that originate from the medial subnucleus. The auricular muscles are innervated by several muscle branches of the facial nerve in addition to the anterior and posterior auricular branches, in the rabbit. There are few identical auricular muscles in the rabbits and rats, aside from $\mathrm{m}$. zygomaticus which is innervated by the buccolabial branch of the facial nerve. However, though $\mathrm{m}$. parietoauricularis is observed only in the rabbit and $\mathrm{m}$. levator auricularis posterioris only in the rat, these muscles act in a similar fashion to elevate and pull the pinna backward. Our findings showed a similar localization of the neurons within the main facial nucleus that innervate these muscles in these species, with subtle differences. Thus, neurons innervating $\mathrm{m}$. parietoauricularis in the rabbit were localized to the ventromadial part of the medial subnucleus while the neurons innervating $\mathrm{m}$. levator auricularis posterioris in the rat were distributed within the medial and ventromedial areas of the medial subnucleus. Our results in the rat are in agreement with the findings of Eckhard's group (1985). The fact that the auricular muscles are mainly innervated by neurons within the medial subnucleus supports the notion that movement of the auricle represents a common motor innervation pattern in mammals. A similar projection scheme was reported in cats and mice (Kume et al., 1978; Komiyama et al., 1984; Tsai et al., 1993).

In conclusion, our findings suggest that there is a common somatotopic organization in the mammalian facial nucleus despite some minor speciesdifferences in the cytoarchitecture of the motor nucleus and the branching pattern of the facial nerve.

\section{References}

1) Courville J. The nucleus of the facial nerve; the relation between cellular groups and peripheral branches of the nerve. Brain Res 1966; 1:338-354.

2) Dom R, Falls W and Matin GF. The motor nucleus of the facial nerve in the opossum (Didelphis marsupialis virginiana), its organization and connections. J Comp Neurol 1973; 152:373-402.

3) Eckhard F and Horst H. Topographic Organization of Facial Motoneurons to Individual Pinna Muscles in Rat (Rat- tus rattus) and Bat (Rousettus aegyptiacus). J Comp Neurol 1985; 240:161-170.

4) Komiyama M, Shibata $H$ and Suzuki T. Somatotopic Representation of Facial Muscles within the Facial Nucleus of the Mouse. Brain Behav Evol 1984; 24:144-151.

5) Kume M, Uemura M, Matsuda $K$, Matsusima $R$ and Mizuno N. Topographycal representation of peripheral branches of the facial nerve within the facial nucleus: a HRP study in the cat. Neurosci Lett 1978; 8:5-8.

6) Martin MR and Lodge D. Morphology of the Facial Nucleus of the Rat. Brain Res 1977; 123:1-12.

7) Matsuda K, Uemura M, Kume M, Matsusima R and Mizuno N. Topographycal representation of masticatory muscle in the motor trigeminal nucleus in the rabbits: a HRP study. Neurosci Lett 1978; 8:1-4.

8) Mesulam MM. The blue reaction product in horseradish peroxidase neurohistochemistry: Incubation parameters and visibility. J Histochem Cytochem 1976; 24:1273-1280.

9) Mesulam MM and Rosene DL. Sensitivity in horseradish peroxidase neurohistochemistry: A comparative and quantitative study of nine methods. J Histochem Cytochem 1979; 27:763-773.

10) Morecraft RJ, Louie JL, Herrick JL and Stilwell-Morecraft KS. Cortical innervation of facial nucleus in the non-human primate: A new interpretation of the effects of stroke and related subtotal brain trauma on the muscles of facial expression. Brain 2001; 124:176-208.

11) Papez JW. Subdivision of the Facial Nucleus. J Comp Neurol 1927; 43:159-191.

12) Provis J. The organization of the facial and scalp muscles in the facial nucleus of the blush-tailed opossum (Trichosurus Vulpecura). J Comp Neurol 1977; 172:177-188.

13) Satoda $T$, Takeuchi $O$, Tashiro $T$, Matsushima $R$, UemuraSumi M and Mizuno N. Somatotopic organization of facial nucleus of rabbit, with particular reference to intranuclear representation of perioral branches of the facial nerve. Anat Anz 1988; 165:83-90.

14) Shohara E and Sakai A. Localization of Motoneurons innervating Deep and Superficial Facial Muscles in the Rat: A Horseradish Peroxidase and Electrophysiologic Study Exp Neurol 1983; 81:14-33.

15) Tsai TC, Wu CH, Wen CY and Shieh JY. Studies of the Motoneurons Following the Injection of Horseradish Peroxidase into the Peripheral Branches of the Facial Nerve in Rats. Acta. Anat. 1993; 148:42-48.

16) Uemura-Sumi M, Manabe $Y$, Matsusima R and Mizuno N. Correlation of the main peripheral branches of the facial nerve with the cytoarchitectonic subdivisions of the facial nucleus in the guinea pig. Anat Embryol 1986; 174:161166.

17) Uemura-Sumi $M$, Itoh $M$ and Mizuno N. The distribution of hypoglossal motoneurons in the dog, rabbit and rat. Anat Embryol 1988; 177:389-394.

18) Watson CRC, Sakai S and Armstrong W. Organization of the facial nucleus in the rat. Brain Behav Evol 1982; 20:19-28.

19) Welt C and Abbs JH. Musculotopic organization of the facial motor nucleus in Macaca fascicularis: A morphometric and retrograde tracing study with cholera toxin BHRP. J Comp Neurol; 291:623-626.

20) William MF and James SK. The facial motor nucleus of the opossum: Cytology and axosomatic synapses. J Comp Neurol 1976; 167:77-204. 